\title{
Yersinia enterocolitica: Mode of Transmission, Molecular Insights of Virulence, and Pathogenesis of Infection
}

\author{
Yeasmin Sabina, ${ }^{1}$ Atiqur Rahman, ${ }^{2}$ Ramesh Chandra Ray, ${ }^{3}$ and Didier Montet ${ }^{4}$ \\ ${ }^{1}$ Department of Genetic Engineering and Biotechnology, University of Dhaka, Dhaka 1000, Bangladesh \\ ${ }^{2}$ Department of Microbiology, University of Dhaka, Dhaka 1000, Bangladesh \\ ${ }^{3}$ Central Tuber Crops Research Institute, Bhubaneswar, India \\ ${ }^{4}$ Centre International de Recherche en Agronomie pour le Developpement (CIRAD), Montpellier, France
}

Correspondence should be addressed to Yeasmin Sabina, y_sabina01@yahoo.com

Received 19 April 2011; Revised 28 May 2011; Accepted 5 June 2011

Academic Editor: Latiful Bari

Copyright ( $) 2011$ Yeasmin Sabina et al. This is an open access article distributed under the Creative Commons Attribution License, which permits unrestricted use, distribution, and reproduction in any medium, provided the original work is properly cited.

\begin{abstract}
Although Yersinia enterocolitica is usually transmitted through contaminated food and untreated water, occasional transmission such as human-to-human, animal-to-human and blood transfusion associated transmission have also identified in human disease. Of the six Y. enterocolitica biotypes, the virulence of the pathogenic biotypes, namely, $1 \mathrm{~B}$ and $2-5$ is attributed to the presence of a highly conserved $70-\mathrm{kb}$ virulence plasmid, termed $\mathrm{pYV} / \mathrm{pCD}$ and certain chromosomal genes. Some biotype 1A strains, despite lacking virulence plasmid ( $\mathrm{pYV}$ ) and traditional chromosomal virulence genes, are isolated frequently from humans with gastrointestinal diseases similar to that produced by isolates belonging known pathogenic biotypes. Y. enterocolitica pathogenic biotypes have evolved two major properties: the ability to penetrate the intestinal wall, which is thought to be controlled by plasmid genes, and the production of heat-stable enterotoxin, which is controlled by chromosomal genes.
\end{abstract}

\section{Introduction}

Yersinia enterocolitica was discovered more than 60 years ago [1] but was not considered as a human or veterinary pathogen until the late 1960s when it became increasingly identified in foodborne gastrointestinal infections [2, 3]. $Y$. enterocolitica is a member of the genus Yersinia which encompasses a heterogeneous collection of facultatively anaerobic bacteria that belong to the family Enterobacteriaceae. Of the 11 species within this genus [4], only three, Y. pestis, Y. pseudotuberculosis, and Y. enterocolitica are regarded as pathogenic for humans whereas Y. ruckeri is a fish pathogen, and $Y$. enterocolitica-like organisms $Y$. krirtensenii, Y. intermedia, Y. mollaretii, Y. frederiksenii and $Y$. bercovieri have yet an unidentified role in human disease [5]. Y. enterocolitica is associated with a wide range of clinical and immunological manifestations, responsible for intestinal diseases, including enterocolitis with an inflammatory diarrhea in affected infants and young children; acute terminal ileitis and mesenteric lymphadenitis mimicking appendicitis in older children and young adults, as well as rare extraintestinal manifestations including urinary tract and respiratory tract infection (empyema), osteoarticular infection (reactive arthritis), erythema nodosum, infected mycotic aneurysm [6-8], axillary abscesses [9], and endocarditis [10].

The geographical distribution of $Y$. enterocolitica is diverse. Y. enterocolitica has more than 50 distinct serotypes (on the basis of antigenic variations in cell wall lipopolysaccharide), and few of them are pathogenic. O:8 is the primary infectious serotype in the USA followed by $0: 3,0: 5,27$, O:13a,13b, O:20, O:9, and so forth [6, 7]. In China, serotype $\mathrm{O}: 3$ is primarily found in infections followed by $\mathrm{O}: 9$ and $\mathrm{O}: 8$ [14]. Furthermore, various serotypes demonstrate geographical specificity; for example, the predominant serotype in Australia, Europe, and Canada is O:3 [5], O:8 in Japan [15], and O:9 in Scandinavia, the Netherlands [16].

The incidence of $Y$. enterocolitica foodborne infection varies according to geography and climate variation. In developed countries, the incidence is higher in infants and 


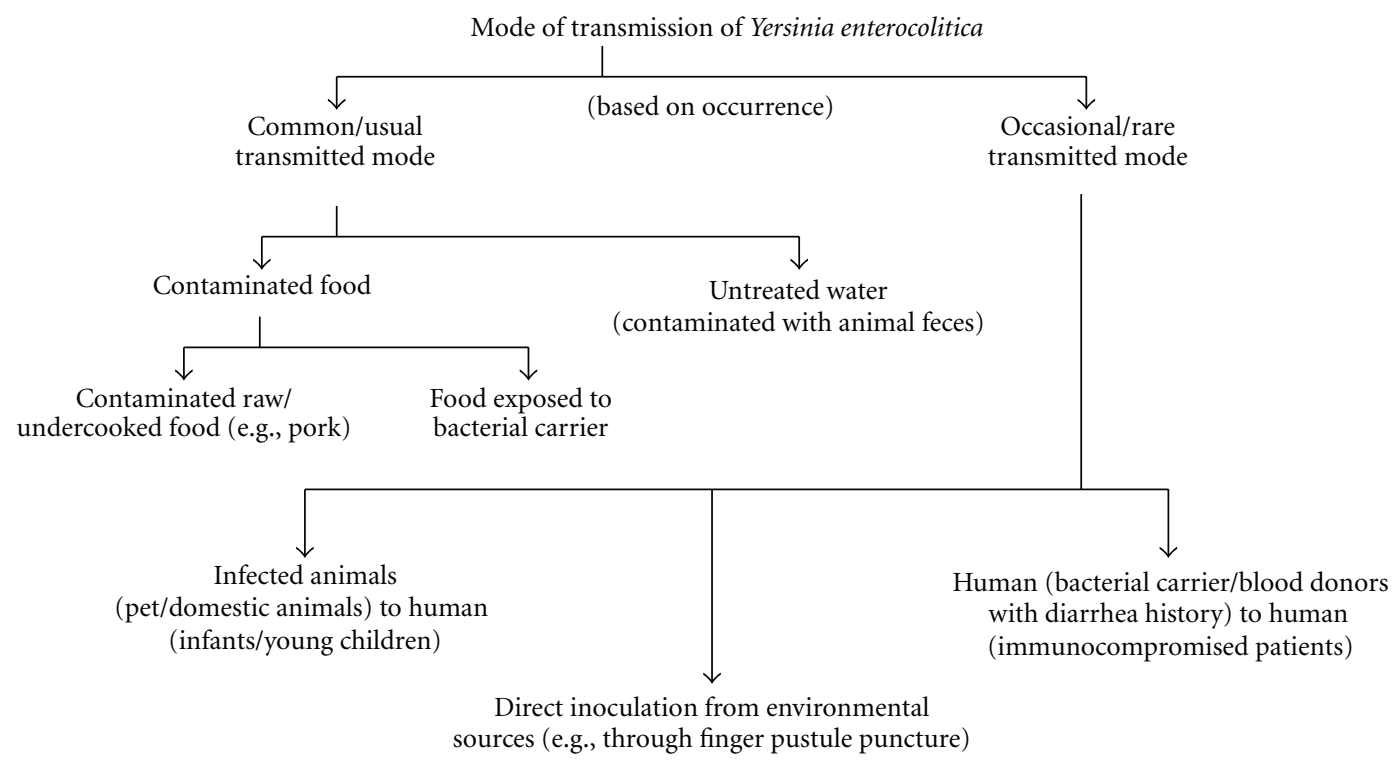

Figure 1: Mode of transmission of Y. enterocolitica.

young children, although all ages are at risk. The majority of foodborne infections are sporadic, and the infection sources are unknown, but large outbreaks have also occurred $[5,17$, 18]. Y. enterocolitica foodborne outbreaks have occurred in Australia, Finland, Japan, Norway, the United States, and Brazil. There were two foodborne outbreaks in China in 1980s; one was caused by beef contamination in Lanzhou of Gansu Province in 1986 with 109 patients with diarrhea caused by $Y$. enterocolitica O:3 infection [19]. The second occurred in a school in Shenyang of Liaoning Province with 352 students having diarrhea caused by $Y$. enterocolitica O:8 infection [14]. Recently, Y. enterocolitica has become of concern worldwide, and foodborne infections have been reported in hundreds of countries.

\section{Mode of Transmission}

2.1. Foodborne Transmission. Y. enterocolitica is an important foodborne human enteropathogen that causes sporadic illness and occasional foodborne outbreaks in the United States whereas incidence of yersiniosis and outbreaks appeared to be higher in many European countries than the United States $[6,20]$. It has been isolated from many foods, including beef, pork, liquid eggs, soft cheese, raw milk, pasteurized milk, fish, raw oysters, shrimps, crabs, chocolate milk, turkey, chow mein (chop suey served with fried noodles), powdered milk, bean sprouts (especially mung beans, lentils, or edible soybeans), and tofu (cheese-like food made of curdled soybean milk). Although the organism has been isolated from many foods, there have been relatively few foodborne outbreaks attributed to $Y$. enterocolitica in developed countries, for example, Japan and the Netherlands $[15,16]$ as well as in developing countries, for example, Bangladesh and Iraq [21, 22]. Human yersiniosis is primarily acquired through the gastrointestinal tract as a result of ingestion of contaminated foods-usually raw or inadequately cooked pork [16]. Y. enterocolitica foodborne outbreaks in the United States have involved young children exposed indirectly during the cleaning and preparation of raw or undercooked pork chitterlings [23]. Chitterlings are generally well cooked, so it is believed that hands, kitchen surfaces, or other kitchen articles contaminated during the preparation of chitterlings are the vehicles for foodborne infection. Survival of Yersinia on these vehicles is facilitated by the hardiness of Yersinia, which is able to multiply in adverse conditions like commercial refrigeration temperatures. Other foodborne outbreaks have been associated with untreated water, contaminated tofu, contaminated bean sprouts, and contaminated milk (unpasteurized or inadequately pasteurized milk) [20]. The isolation of Yersinia strains from contaminated milk can be probably the result of postpasteurization contamination, since even the most heat-resistant strains are reported to be killed by pasteurization (Figure 1).

2.2. Human-to-Human Transmission. Person-to-person transmission is rare. However, contamination of food by infected food handler and nosocomial infections have been reported. In July 2006, person-to-person transmission was observed in a familial outbreak of $Y$. enterocolitica bioserotype 2/O:9 in Japan [24]. The possible source of this infection was an infected carrier who suffered from diarrhea [24]. In addition, the outbreak of diarrheal disease due to Yersinia enterocolitica bioserotype 1/0:5 was reported in hospitalized patients, which was the indication of a nosocomial outbreak due to Yersinia enterocolitica [25].

2.3. Animal-to-Human Transmission and Waterborne Transmission. Occasionally Y. enterocolitica infection occurs after direct or indirect contact with infected animals. It has been isolated from the intestinal tracts and feces of many animals, including rodents (rabbits), domestic animals (e.g., sheep, cattle, cats, pigs, and dogs) [26], and other animals 
(deer, raccoons, and horses) and water contaminated by those animals. The pig appears to be the main reservoir for the strains causing infection in humans. Pig feces are a potential mode of direct transmission to farmers [27]. As $Y$. enterocolitica possess the ability to grow under extreme environmental condition, they are welladapted to survival in cooler temperate zones as well as in microaerophilic environments including aquatic environments.

2.4. Direct Transmission. Y. enterocolitica rarely causes extraintestinal disease. In case of extraintestinal disease, direct transmission is proposed as the mode of transmission of this classically enteric pathogen [9]. In January 2009, a 54year-old African American construction worker with chronic hepatitis $\mathrm{C}$ developed an axillary abscess due to $Y$. enterocolitica that followed an injury to his finger. It was proposed that the finger pustule arising as a consequence of traumatic puncture presented the possibility that direct inoculation of $Y$. enterocolitica from an environmental source may have been the mode of transmission. These suggest an alternative nonfoodborne route for $Y$. enterocolitica transmission. A similar route of transmission was proposed for a patient with Y. enterocolitica axillary abscess whose employment as a butcher subjected him to frequent cut wounds to the hand [28].

2.5. Blood Transfusion-Associated Transmission. Yersinia enterocolitica can be transmitted through contaminated blood, and it was one of the first recognized causes of posttransfusion sepsis [29]. This first case of transfusion-associated sepsis caused by $Y$. enterocolitica was described in the Netherlands in 1975. Since then, more than 60 additional cases have been reported in the literature worldwide. Y. enterocolitica has occurred occasionally in donor blood from healthy donors or donors with a diarrhea history; such contaminated blood sometimes caused Yersinia bacteremia and death of the recipients [30]. Although fatality due to posttransfusion bacterial-associated sepsis is rare [31], blood-transfusionassociated septicemia due to $Y$. enterocolitica is reported to have high fatality rate. In 2003, a fatal case of septic shock was observed in a 71-year-old patient following transfusion of contaminated red blood cells (RBCs) for refractory anemia. $Y$. enterocolitica bioserotype 4/O:3 was isolated from the patient's blood sample and the transfused RBCs. High titers of antibodies against $Y$. enterocolitica were detected in the donor's plasma sample one month after blood donation. The donor reported abdominal discomfort 3.5 months before blood collection but had no clinical signs of intestinal infection at the time of donation [32].

\section{Molecular Insights in Virulence}

Yersinia enterocolitica has evolved into an apparently heterogeneous collection of organisms encompassing six biotypes differentiated by physiochemical and biochemical tests $(1 \mathrm{~A}, 1 \mathrm{~B}, 2,3,4$, and 5 ; Table 1$)$ and more than 50 serotypes differentiated by antigenic variation in cell wall lipopolysaccharide. Of the six biotypes, biotype $1 \mathrm{~A}$ is the most heterogeneous, and encompasses a wide range of serotypes (Table 2), of which serotypes O:5, O:6,30, O:6,31, $\mathrm{O}: 7,8, \mathrm{O}: 10$, as well as O-nontypable strains, are isolated most often [33]. The virulence of the pathogenic biotypes, namely, $1 \mathrm{~B}$ and $2-5$ is attributed to the presence of a highly conserved $70-\mathrm{kb}$ virulence plasmid, termed $\mathrm{pYV} / \mathrm{pCD}$ and certain chromosomal genes [42] (Table 3). The biotype 1A strains of $Y$. enterocolitica, on the other hand, have been reported to lack pYV plasmid which encodes virulence factors including Yersinia adhesin A (YadA) and Ysc-Yop type III secretion system (TTSS) as well as chromosomally borne virulence genes including ail, myfA, ystA, ysa, and the high pathogenicity island- (HPI-) associated iron acquisition system [35] (Figure 2).

3.1. Virulence Factors of $p Y V$-Bearing Strains of $Y$. enterocolitica [33]. Apart from pYV itself, pYV-bearing strains of $Y$. enterocolitica require a number of chromosomally borne genes to express full virulence. Some of these virulence genes are restricted to pYV-bearing bacteria whereas others occur more widely. Virulence genes that are mostly limited to pYV-bearing strains of $Y$. enterocolitica include inv (encodes invasin, an outer membrane protein that is required for efficient translocation of bacteria across the intestinal epithelium) [43]); ail (encodes another outer membrane protein that may contribute to adhesion, invasion, and resistance to complement-mediated lysis) [44]; yst (encodes Yersinia stable heat-stable enterotoxin that may contribute to the pathogenesis of diarrhea associated with acute yersiniosis) $[45,46]$; myf (encodes a fimbrial antigen and putative adhesin) [47]. In addition, strains of biotype 1B, which are particularly virulent for humans and laboratory animals, carry a high-pathogenicity island (HPI) which facilitates the uptake and utilization of iron by bacterial cells, and hence may promote their growth under iron-limiting conditions in host tissues [48]. Virulence-associated determinants of pYV-bearing Y. enterocolitica that also occur in pYV-negative strains include cell surface lipopolysaccharide and SodA (a superoxide dismutase), which appear to facilitate bacterial survival in tissues $[49,50]$, as well as urease, which enhances bacterial resistance to stomach acid and may also play a role in nitrogen assimilation [51].

pYV functions mainly as an antihost plasmid that permits the bacteria which carry it to resist to phagocytosis and complement-mediated lysis, thus allowing them to proliferate extracellularly in tissues. The pYV plasmidencoded virulence factors include an outer membrane protein adhesin, YadA, and a type III protein secretory apparatus which translocates effector proteins, known as Ysc-Yops, from the bacterial cell to the cytoplasm of susceptible host cells [42]. The contribution of pYV-encoded factors, in particular YadA and the Yop effectors, to bacterial virulence has been established in a large number of studies. Strains of Yersinia which lack pYV are susceptible to killing by complement and polymorphonuclear leukocytes, although they are able to persist in macrophages and nonprofessional phagocytic cells, and cause short-lived infections which are typically asymptomatic [52]. 
TABLE 1: Biotyping scheme of Y. enterocolitica (adapted from $[33,34]$ ).

\begin{tabular}{|c|c|c|c|c|c|c|}
\hline \multirow{2}{*}{ Test } & \multicolumn{6}{|c|}{ Reaction of biotype } \\
\hline & $1 \mathrm{~A}$ & $1 \mathrm{~B}$ & 2 & 3 & 4 & 5 \\
\hline Lipase (Tween hydrolysis) & + & + & - & - & - & - \\
\hline Aesculin hydrolysis & $\mathrm{V}$ & - & - & - & - & - \\
\hline Indole production & + & + & $(+)$ & - & - & - \\
\hline D-Xylose fermentation & + & + & + & + & - & $\mathrm{v}$ \\
\hline Voges-Proskauer reaction & + & + & + & + & + & $(+)$ \\
\hline Trehalose fermentation & + & + & + & + & + & - \\
\hline Nitrate reduction & + & + & + & + & + & - \\
\hline Pyrazinamidase & + & - & - & - & - & - \\
\hline B-D-Glucosidase & + & - & - & - & - & - \\
\hline Proline peptidase & $\mathrm{v}$ & - & - & - & - & - \\
\hline
\end{tabular}

+, positive; (+), delayed positive; -, negative; $\mathrm{v}$, variable reactions.

TABLE 2: Relationship between biotype, O serotype, and pYV carriage of Y. enterocolitica (adapted from Sharon et al. 2003).

\begin{tabular}{|c|c|}
\hline Biotype & Serotype(s) \\
\hline $1 \mathrm{~A}$ & O:4; O:5; O:6,30; O6,31; O:7,8; O:7,13; O:10; O:14; O:16; O:21; O:22; O:25; O:37; O:41,42; O:46; O:47; O:57; NT \\
\hline $1 \mathrm{~B}$ & $\mathrm{O}: 4,32^{\mathrm{b}} ; \mathrm{O}: 8^{\mathrm{b}} ; \mathrm{O}: 13 \mathrm{a}, 13 \mathrm{~b}^{\mathrm{b}} ; \mathrm{O}: 16 ; \mathrm{O}: 18^{\mathrm{b}} ; \mathrm{O}: 20^{\mathrm{b}} ; \mathrm{O}: 21^{\mathrm{b}} ; \mathrm{O}: 25 ; \mathrm{O}: 41,42 ; \mathrm{NT}$ \\
\hline 2 & $\mathrm{O}: 5,27^{\mathrm{b}} ; \mathrm{O}: 9^{\mathrm{b}} ; \mathrm{O}: 27$ \\
\hline 3 & $\mathrm{O}: 1,2,3^{\mathrm{b}} ; \mathrm{O}: 3^{\mathrm{b}} ; \mathrm{O}: 5,27^{\mathrm{b}}$ \\
\hline 4 & $\mathrm{O}: 3^{\mathrm{b}}$ \\
\hline 5 & $\mathrm{O}: 2,3^{\mathrm{b}}$ \\
\hline
\end{tabular}

${ }^{a} \mathrm{NT}$, not typable.

${ }^{\mathrm{b}}$ Serotypes which include strains that carry pYV.

TABLE 3: Virulence-associated genes in Y. enterocolitica.

\begin{tabular}{|c|c|c|}
\hline Genes & Gene product/function & Reference \\
\hline $\operatorname{Inv} v^{C, t r}$ & $\begin{array}{l}\text { Invasin (an outer membrane protein that is required for efficient translocation of bacteria across the } \\
\text { intestinal epithelium) }\end{array}$ & {$[35]$} \\
\hline$a i l^{C, t r}$ & $\begin{array}{l}\text { Adhesin (outer membrane protein that may contribute to adhesion, invasion, and resistance to } \\
\text { complement-mediated lysis) }\end{array}$ & [36] \\
\hline $\operatorname{vir} F^{C, t r}$ & Transcriptional activator & {$[36]$} \\
\hline$m y f A^{C}$ & Mucoid Yersinia factor (fimbrial antigen and putative adhesin) & {$[37]$} \\
\hline$y s t A^{C, t r}$ & Enterotoxin (Yersinia stable heat-stable toxin that may contribute to the pathogenesis of diarrhea) & {$[38]$} \\
\hline$y s t B^{C}$ & Enterotoxin (Yersinia stable heat-stable toxin that may contribute to the pathogenesis of diarrhea) & {$[38]$} \\
\hline$y s t C^{C}$ & Enterotoxin (Yersinia stable heat-stable toxin that may contribute to the pathogenesis of diarrhea) & [39] \\
\hline fepA & Enterochelin receptor protein & {$[40]$} \\
\hline$f e d D$ & Enterochelin receptor protein & {$[40]$} \\
\hline Fes & Enterochelin esterase & {$[40]$} \\
\hline $\operatorname{tcc} C^{P}$ & Insecticidal toxin-like protease & {$[35]$} \\
\hline$y m o A$ & Yersinia modulator & {$[41]$} \\
\hline hreP & Subtilisin/kexin-like protease (host responsive element) & {$[35]$} \\
\hline Sat & Streptogramin acetyltranferase & {$[35]$} \\
\hline$y a d A^{P, t r}$ & Yersinia adhesin A & {$[42]$} \\
\hline$y s a^{P}$ & Yesinia secretion apparatus & {$[42]$} \\
\hline
\end{tabular}

${ }^{C}$ Chromosome borne gene, ${ }^{P}$ plasmid-borne gene, ${ }^{\text {tr }}$ traditional virulence gene. 


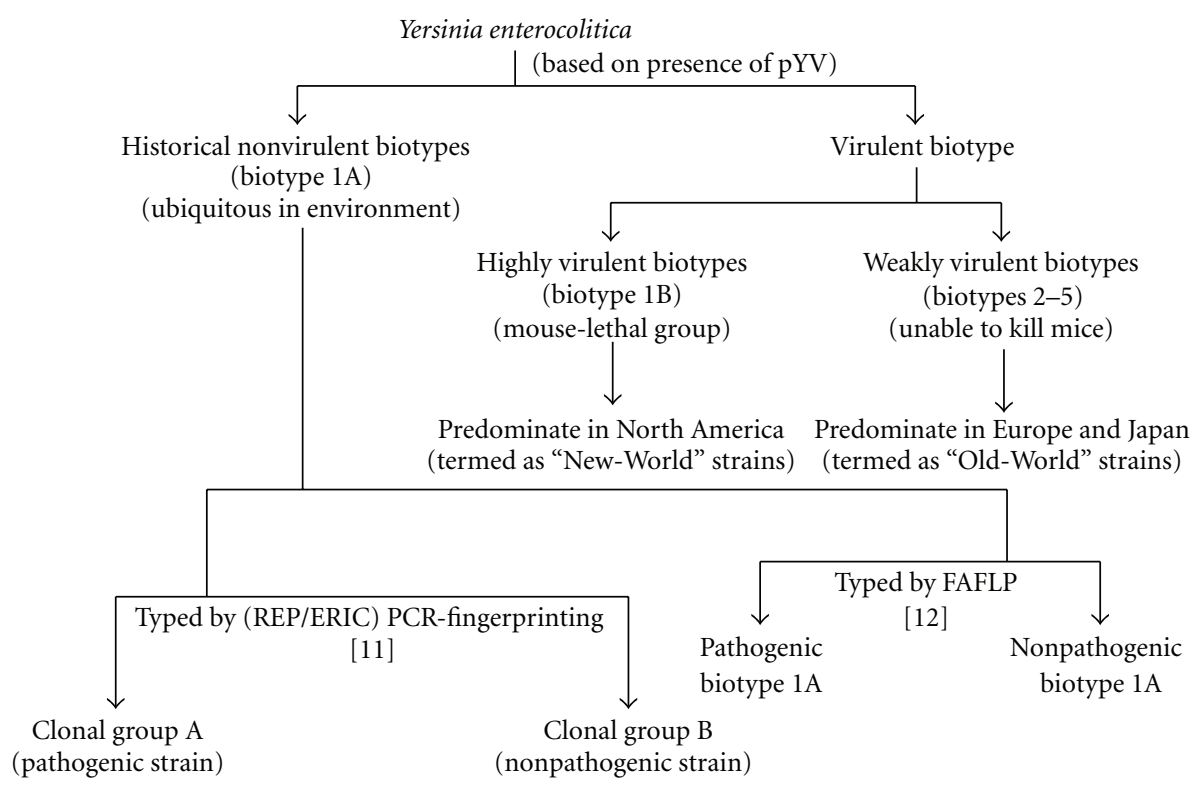

FIGURE 2: Y. enterocolitica biotypes. Y. enterocolitica biotypes are classified into three distinct group: a historically defined nonpathogenic group (biogroup 1A); a weakly pathogenic group that are unable to kill mice (biogroups 2 to 5); a highly pathogenic, mouse-lethal group (biogroup 1B). Biotype 1A strains are clustered into two clonal groups (A and B) when typed by repetitive extragenic palindrome (REP) and enterobacterial repetitive intergenic consensus (ERIC)_PCR fingerprinting [11], and two groups when typed by fluorescent amplified fragment length polymorphism (FAFLP) [12].

3.2. Evidence Indicating the Lack of Virulence of Biotype 1 A Strains. Biotype 1A strains of Y. enterocolitica are often considered to be nonpathogenic primarily because they do not possess the virulence-associated factors of pYV-bearing strains. The biotype 1A strains have been reported to lack both pYV plasmid and most chromosomal virulence genes such as ail, myfA, ystA, ysa, TTSS, and HPI, and only occasionally carry $y s t A$ and myfA [53]. Although the ail gene is present in some biotype $1 \mathrm{~A}$ strains, the ail gene alone is an insufficient virulence marker for detecting the virulence of $Y$. enterocolitica biotype 1A strains [54]. Another line of evidence that is taken to indicate the avirulence of biotype 1A strains is their relatively high prevalence in the environment and healthy animals. Indeed, biotype 1A strains are ubiquitous, inhabiting a wide variety of environmental niches such as soil and various sources of water, including streams, lakes, water wells, and wastewater $[55,56]$ Sharon et al. 2003. They are also frequently isolated from foods, including various vegetables and animal products, such as pork, poultry, packaged meat, seafood, raw milk, and pasteurized dairy products. Biotype1A are also found in a vast array of animals, including birds, fish, various insects, frogs, and a wide range of mammals, including cattle, sheep, pigs, and rodents. In most cases, animals infected with biotype 1A strains are asymptomatic, thus giving support to the concept that these bacteria are avirulent commensals [33] (Table 4).

3.3. Some Studies Indicating the Pathogenicity in Some Y. enterocolitica Biotype 1 A Strains. Despite the lack of traditional chromosomal-borne and plasmid-borne virulence genes in $Y$. enterocolitica strains of biotype 1A, some biotype 1A strains are isolated frequently from humans with gastrointestinal diseases. The biotype 1A strains isolated from humans and from pigs have been reported to produce ystB-encoding Yersinia heat-stable enterotoxin [53]. A recent study on 259 isolates of $Y$. enterocolitica and related species; indicated that Yst-B $(y s t B)$ was the major contributor to diarrhea produced by biotype $1 \mathrm{~A}$ strains of $Y$. enterocolitica [62]. Some biotype 1A strains produce symptoms indistinguishable from that produced by isolates belonging to pathogenic biotypes $[63,64]$. Biotype $1 \mathrm{~A}$ strains have also been implicated in nosocomial [25] and foodborne [65] outbreaks, and were also isolated from extraintestinal infections [66].

\section{Pathogenesis}

Yersinia enterocolitica pathogenesis is incompletely understood. Most isolates of $Y$. enterocolitica from food or clinical materials have either of two pathogenic properties. First property is the ability to penetrate the intestinal wall, which is thought to be controlled by $70-\mathrm{kb}$ virulence plasmid (pYV/pCD) genes; that is absent in avirulent strains; second one is the production of heat-stable enterotoxin which is controlled by chromosomal genes ( $y s t A, y s t B$, and $y s t C)$ [61].

4.1. Adaptation. As contaminated foods are considered as the common mode of transmission, this microorganism must first adapt its surface antigenic structures like outer membrane proteins to colonize in the intestines of humans 
TABLE 4: Studies indicating the lack of virulence of biotype 1A strains.

Research studies

References

(1) Two large studies in Belgium, involving the microbiological investigation of more than 24,000 fecal samples over a period of almost 16 years, revealed that infection with biotype $1 \mathrm{~A}$ was not associated with gastrointestinal symptoms and that biotype 1A strains were more frequent amongst subjects having no gastrointestinal complaints.

(2) Rabbits were infected perorally with different biotype 1A strains from raw fish (serotype O:6,30) and pig intestine (serotype O:5), respectively, and concluded that these bacteria were avirulent.

(3) Robins-Browne et al. reported that gnotobiotic piglets, inoculated perorally with a biotype 1A strain of serotype O:5, which was originally isolated from milk, rapidly cleared the bacteria without developing any clinical or pathological evidence of disease.

Van Noyen et al. $[57,58]$

Pai et al. [59]Une [60]

Robins-Browne et al. [61] at a temperature of about $37^{\circ} \mathrm{C}$. This is usually achieved in part through the presence of $70-\mathrm{kb}$ virulence plasmid (pYV). Genes on this plasmid encode for several outer membrane proteins (polypeptides) that are expressed at $37^{\circ} \mathrm{C}$ but not at $25^{\circ} \mathrm{C}[6]$.

4.2. Adhesion. Attachment of pYV-bearing strains (pathogenic biotypes $1 \mathrm{~B}$ and 2-5) of $Y$. enterocolitica to tissue culture cells like HeLa cells or HEp-2 cells cultures has been frequently identified in pathogenic Yersinia isolates $[5,67,68]$. However, the ability to produce disease does not correlate with HeLa cell attachment as plasmid cured avirulent strains retain the ability to attach to HeLa cells [69]. When the pYV plasmid-containing strain was grown at $26^{\circ} \mathrm{C}$ in calcium-containing medium, the bacteria adhered to HeLa cells and HEp-2 cell cultures to a high degree. In contrast, when this strain was incubated at $37^{\circ} \mathrm{C}$ in the same calcium-containing medium, it attached to the HeLa cells and HEp-2 cell cultures at a reduced level [70]. By insertional inactivation of genes located on the virulence plasmid (pYV), Kapperud et al. [71] identified four plasmiddependent and temperature-inducible properties related to the bacterial surface properties involved in fimbrial adhesion: (i) a fimbrial matrix covering the outer membrane, (ii) outer membrane protein, YOP1 which is a structural component of the fimbriae, (iii) spontaneous autoagglutination, which is related to the fimbriae, and (iv) mannose-resistant hemagglutination of guinea pig erythrocytes [71].

Although the biotype $1 \mathrm{~A}$ strains of $Y$. enterocolitica have been reported to lack pYV plasmid, various forms of fimbriae are observed in this biotype. One of fimbriae, designated $\mathrm{MR} / \mathrm{Y}-\mathrm{HA}$ is $8 \mathrm{~nm}$ in diameter, agglutinates erythrocytes of 10 different animal species in the presence of mannose and is expressed in vitro at low temperature, but not at $37^{\circ} \mathrm{C}[72]$. A second type of fimbriae, designated $\mathrm{MR} / \mathrm{K}-$ like $\mathrm{HA}$, is $4 \mathrm{~nm}$ in diameter and mediates mannoseresistant hemagglutination of chicken erythrocytes, but not erythrocytes from a variety of other species [72]. Expression of these fimbriae in vitro occurs only after serial passages of bacteria for at least 7 days. Moreover, as they do not mediate adherence of bacteria to cultured epithelial cells [73], their contribution to the pathogenesis of infection with biotype 1A strains is unknown [33].

Some strains of $Y$. enterocolitica produce a fimbrial adhesin, named Myf (for mucoid Yersinia fibrillae), because

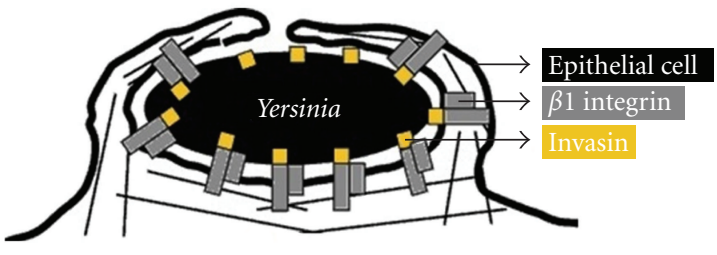

FIGURE 3: A paradigm of "zippering" entry of a bacterial pathogen into epithelial cells. Invasin mediated binding of Yersinia to $\beta 1$ integrins and internalization (adapted from [13]).

it bestows a mucoid appearance on bacterial colonies which express it. Myf are narrow flexible fimbriae which resemble CS3, an essential colonization factor of some human clinical strains of enterotoxigenic Escherichia coli [33]. However, myf genes-associated virulence of these bacteria is unknown.

\subsection{Invasiveness (Mechanisms of Epithelial Cell Invasion).} Entry of enteroinvasive bacteria into the intestinal epithelial cell is the key to a successful invasive process. The ability of Y. enterocolitica to invade epithelial cells is an important correlation of pathogenicity [8]. The invasive process includes a major signalling process that an invasive microorganism may provoke to force its way into a nonphagocytic cell, and then disrupting and invading the intestinal barrier, a process that involves interaction with other cellular components of this barrier. There are essentially two major mechanisms of bacterial epithelial cell internalization [74] The "zippering" process corresponds to tight enclosing of the bacterial cell by the mammalian cell membrane, involving a surface bound bacterial protein binding an adherence molecule of the mammalian cell surface with high affinity - that is, the invasin (Inv) of Yersinia binding integrins of the $\beta 1$ family of mammalian cell surface [75]. One reason that strains of biotype 1A have been considered to be avirulent is that they invade tissue culture cells to a lesser extent than pYV-bearing strains $[69,76]$. However, paradoxically, some pYV-bearing strains themselves may retard mammalian epithelial cell invasion via the effects of translocated Yops on cytoskeletal proteins [42] as well as some biotype 1A strains are positive for the ail gene encoded an outer membrane protein that may contribute to epithelial cell adhesion and invasion [77] (Figure 3). 

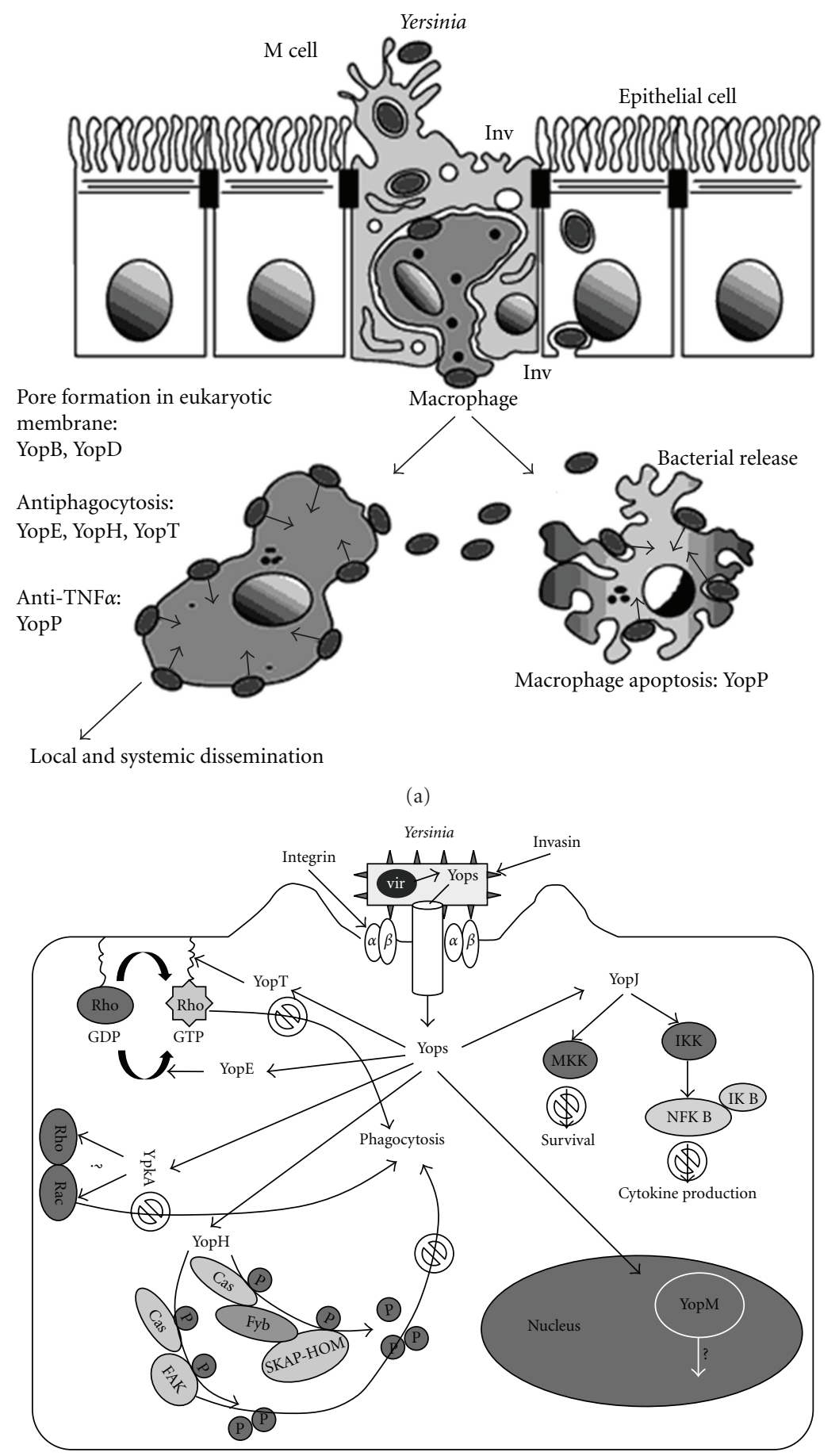

(b)

FIgure 4: Physiopathological scheme of Yersinia infection. The Yops are delivered into the host cells via a type III secretion system. YopH, a tyrosine phosphatase, dephosphorylates Cas and FAK (protein tyrosine kinase) in epithelial cells, and Cas, Fyb, and SKAP-HOM in macrophages that are involved in the assembly of cytoskeletal complexes required for phagocytosis [78]; YopT modifies the Rho family GTPases by inducing redistribution of the RhoA GTPase [79]; YopE inactivates the Rho family of GTPases involved in phagocytosis [80]; YpkA binds to Rac and Rho (function unknown). These four Yops alter or disrupt the actin cytoskeleton and thereby block phagocytosis. YopJ impairs activation of MAPKKs and NF-B, which induces apoptosis and inhibits cytokine production. YopM is translocated into the nucleus (function unknown; adapted from [13]). 
4.4. Local and Systemic Dissemination. Y. enterocolitica usually causes a diarrheal disease, and sometimes systemic diffusion. Yersinia virulent strains cross the intestinal epithelium primarily through the FAE (follicle associated epithelial cell), in the Peyer's patches of the ileum [81]. Invasin (Inv), a $103 \mathrm{kDa}$ outer membrane protein of Yersinia binds $\beta 1$ integrins that are also expressed apically on $\mathrm{M}$ cells. Inv negative mutants still adhere to and invade $M$ cells, but at a much lower level than the wildtype strain and their colonization potential for Peyer's patches is considerably reduced [82]. Other Yersinia surface proteins such as Ail, PsaA, and YadA may account for residual invasion of inv mutants [83]. After invasion process, Yersinia defend the attack by resident macrophages by expressing an antiphagocytic strategy mediated by a plasmid encoded type III secretion, of three protein effectors, YopH, T, and E, that disrupt cytoskeletal assembly required for phagocytosis process $[84,85]$. Yersinia strains therefore remain extracellular in infected Peyer's patches and mesenteric lymph nodes, and then disseminate to cause local and systemic infection (Figure 4).

\section{Conclusion}

Yersinia enterocolitica is most often transmitted by consumption of contaminated food (most commonly raw or undercooked pork), unpasteurized milk or inadequately pasteurized milk, untreated water, or by direct or indirect contact with animals. The virulence of $Y$. enterocolitica strains mostly depends on the presence of pYV plasmid. Y. enterocolitica $\mathrm{pYV}$-positive strains contain plasmid-mediated virulence genes involved in developing infection especially in gastrointestinal tract with the help of traditional chromosomal genes whereas pYV-negative strains are mostly noninfectious except heat-stable enterotoxin-producing strain.

\section{References}

[1] J. I. Schleifstein and M. B. Coleman, "Unidentified microorganisms resembling B. lignieri and Pasteurella pseudotuberculosis, pathogenic for man," New York State Journal of Medicine, vol. 39, pp. 1749-1753, 1939.

[2] S. Toma and L. Lafleur, "Survey on the incidence of Yersinia enterocolitica infection in Canada," Journal of Applied Microbiology, vol. 28, no. 3, pp. 469-473, 1974.

[3] B. A. Kay, K. Wachsmuth, P. Gemski, J. C. Feeley, T. J. Quan, and D. J. Brenner, "Virulence and phenotypic characterization of Yersinia enterocolitica isolated from humans in the United States," Journal of Clinical Microbiology, vol. 17, no. 1, pp. 128$138,1983$.

[4] G. Wauters, M. Janssens, A. G. Steigerwalt, and D. J. Brenner, "Yersinia mollaretii sp. nov. and Yersinia bercovieri sp. nov., formerly called Yersinia enterocolitica biogroups 3A and 3B," International Journal of Systematic Bacteriology, vol. 38, no. 4, pp. 424-429, 1988.

[5] E. V. O', D. G. Gall, and C. H. Pai, "Review article: Yersinia enterocolitica: mechanisms of microbial pathogenesis and pathophysiology of diarrhoea," Journal of Gastroenterology and Hepatology, vol. 5, no. 2, pp. 173-179, 1990.

[6] E. J. Bottone, "Yersinia enterocolitica: the charisma continues," Clinical Microbiology Reviews, vol. 10, no. 2, pp. 257-276, 1997.
[7] J. Kwaga, J. O. Iversen, and V. Misra, "Detection of pathogenic Yersinia enterocolitica by polymerase chain reaction and digoxigenin-labeled polynucleotide probes," Journal of Clinical Microbiology, vol. 30, no. 10, pp. 2668-2673, 1992.

[8] V. L. Miller, J. J. Farmer III, W. E. Hill, and S. Falkow, "The aid locus is found uniquely in Yersinia enterocolitica serotypes commonly associated with disease," Infection \& Immunity, vol. 57, no. 1, pp. 121-131, 1989.

[9] B. E. Menzies, "Axillary abscess due to Yersinia enterocolitica," Journal of Clinical Microbiology, vol. 48, no. 9, pp. 3438-3439, 2010.

[10] V. Krajinović, A. A. Tambić, and B. Barśić, "Tricuspidal valve endocarditis due to Yersinia enterocolitica," Infection, vol. 35, no. 3, pp. 203-205, 2007.

[11] P. Sachdeva and J. S. Virdi, "Repetitive elements sequence (REP/ERIC)-PCR based genotyping of clinical and environmental strains of Yersinia enterocolitica biotype 1A reveal existence of limited number of clonal groups," FEMS Microbiology Letters, vol. 240, no. 2, pp. 193-201, 2004.

[12] C. Fearnley, S. L. W. On, B. Kokotovic, G. Manning, T. Cheasty, and D. G. Newell, "Application of fluorescent amplified fragment length polymorphism for comparison of human and animal isolates of Yersinia enterocolitica," Applied and Environmental Microbiology, vol. 71, no. 9, pp. 4960-4965, 2005.

[13] P. Sansonetti, "Host-pathogen interactions: the seduction of molecular cross talk," Gut, vol. 50, no. 3, pp. iii2-iii8, 2002.

[14] X. Wang, H. Qiu, D. Jin et al., "O:8 serotype Yersinia enterocolitica strains in China," International Journal of Food Microbiology, vol. 125, no. 3, pp. 259-266, 2008.

[15] T. Sakai, A. Nakayama, M. Hashida, Y. Yamamoto, H. Takebe, and S. Imai, "Outbreak of food poisoning by Yersinia enterocolitica serotype O8 in Nara Prefecture: the first case report in Japan," Japanese Journal of Infectious Diseases, vol. 58, no. 4, pp. 257-258, 2005.

[16] D. Grahek-Ogden, B. Schimmer, K. S. Cudjoe, K. Nygard, and G. Kapperud, "Outbreak of Yersinia enterocolitica serogroup O:9 infection and processed pork, Norway," Emerging Infectious Diseases, vol. 13, no. 5, pp. 754-756, 2007.

[17] M. Shayegani, D. Morse, I. DeForge, T. Root, L. Parsons, and P. S. Maupin, "Microbiology of a major foodborne outbreak of gastroenteritis caused by Yersinia enterocolitica serogroup 0:8," Journal of Clinical Microbiology, vol. 17, pp. 35-40, 1983.

[18] R. E. Black, R. J. Jackson, T. Tsai et al., "Epidemic Yersinia enterocolitica infection due to contaminated chocolate milk," The New England Journal of Medicine, vol. 298, no. 2, pp. 7679, 1978.

[19] B. Dian, R. H. Jin, W. Y. Pang et al., "The first outbreak of Yersinia enterocolitica in China," Chinese Journal of Zoonoses, vol. 3, pp. 2-4, 1987.

[20] T. L. Cover and R. C. Aber, "Yersinia enterocolitica," The New England Journal of Medicine, vol. 321, no. 1, pp. 16-24, 1989.

[21] T. Butler, M. Islam, M. R. Islam et al., "Isolation of Yersinia enterocolitica and Y. intermedia from fatal cases of diarrhoeal illness in Bangladesh," Transactions of the Royal Society of Tropical Medicine and Hygiene, vol. 78, no. 4, pp. 449-450, 1984.

[22] T. A. Kanan and Z. A. Abdulla, "Isolation of Yersinia spp. from cases of diarrhoea in Iraqi infants and children," Eastern Mediterranean Health Journal, vol. 15, no. 2, pp. 276-284, 2009.

[23] L. A. Lee, A. R. Gerber, D. R. Lonsway et al., "Yersinia enterocolitica O:3 infections in infants and children, associated with the household preparation of chitterlings," The New 
England Journal of Medicine, vol. 322, no. 14, pp. 984-987, 1990.

[24] S. Moriki, A. Nobata, H. Shibata et al., "Familial outbreak of Yersinia enterocolitica serotype O9 biotype 2," Journal of Infection and Chemotherapy, vol. 16, no. 1, pp. 56-58, 2010.

[25] S. Ratnam, E. Mercer, B. Picco, S. Parsons, and R. Butler, "A nosocomial outbreak of diarrheal disease due to Yersinia enterocolitica serotype O:5, biotype 1," Journal of Infectious Diseases, vol. 145, no. 2, pp. 242-247, 1982.

[26] X. Wang, Z. Cui, H. Wang et al., "Pathogenic strains of Yersinia enterocolitica isolated from domestic dogs (Canis familiaris) belonging to farmers are of the same subtype as pathogenic $Y$. enterocolitica strains isolated from humans and may be a source of human infection in Jiangsu Province, China," Journal of Clinical Microbiology, vol. 48, no. 5, pp. 1604-1610, 2010.

[27] J. Chin, Yersiniosis/Intestinal Yersiniosis/ Extraintestinal Yersiniosis. Control of Communicable Diseases Manual, vol. 17, American Public Health Association, Washington, DC, USA, 2000.

[28] T. Kelesidis, G. Balba, and M. Worthington, "Axillary abscess in a patient with Yersinia enterocolitica infection as a result of exposure to pork," American Journal of Medicine, vol. 121, no. 3, p. e1, 2008.

[29] A. Bruining and C. C. M. De Wilde-Huizen, "A case of contamination of donor blood by Yersinia enterocolitica type 9," Medikon Nederland, vol. 4, pp. 25-26, 1975.

[30] J. Jacobs, D. Jamaer, J. Vandeven, M. Wouters, C. Vermylen, and J. Vandepitte, "Yersinia enterocolitica in donor blood: a case report and review," Journal of Clinical Microbiology, vol. 27, no. 5, pp. 1119-1121, 1989.

[31] M. A. Tipple, L. A. Bland, J. J. Murphy et al., "Sepsis associated with transfusion of red cells contaminated with Yersinia enterocolitica," Transfusion, vol. 30, no. 3, pp. 207-213, 1990.

[32] A. Leclercq, L. Martin, M. L. Vergnes et al., "Fatal Yersinia enterocolitica biotype 4 serovar O:3 sepsis after red blood cell transfusion,” Transfusion, vol. 45, no. 5, pp. 814-818, 2005.

[33] S. M. Tennant, T. H. Grant, and R. M. Robins-Browne, "Pathogenicity of Yersinia enterocolitica biotype 1A," FEMS Immunology and Medical Microbiology, vol. 38, no. 2, pp. 127137, 2003.

[34] G. Wauters, K. Kandolo, and M. Janssens, "Revised biogrouping scheme of Yersinia enterocolitica," Contributions to Microbiology and Immunology, vol. 9, pp. 14-21, 1987.

[35] N. Bhagat and J. S. Virdi, "Distribution of virulence-associated genes in Yersinia enterocolitica biovar 1A correlates with clonal groups and not the source of isolation," FEMS Microbiology Letters, vol. 266, no. 2, pp. 177-183, 2007.

[36] S. Bhaduri, B. Cottrell, and A. R. Pickard, "Use of a single procedure for selective enrichment, isolation, and identification of plasmid-bearing virulent Yersinia enterocolitica of various serotypes from pork samples," Applied and Environmental Microbiology, vol. 63, no. 5, pp. 1657-1660, 1997.

[37] B. Kot and E. A. Trafny, "The application of PCR to the identification of selected virulence markers of Yersinia genus," Polish Journal of Veterinary Sciences, vol. 7, no. 1, pp. 27-31, 2004.

[38] P. Thoerner, C. I. B. Kingombe, K. Bogli-Stuber et al., "PCR detection of virulence genes in Yersinia enterocolitica and Yersinia pseudotuberculosis and investigation of virulence gene distribution," Applied and Environmental Microbiology, vol. 69, no. 3, pp. 1810-1816, 2003.

[39] X. Huang, K. I. Yoshino, H. Nakao, and T. Takeda, "Nucleotide sequence of a gene encoding the novel Yersinia enterocolitica heat-stable enterotoxin that includes a pro-region-like sequence in its mature toxin molecule," Microbial Pathogenesis, vol. 22, no. 2, pp. 89-97, 1997.

[40] S. Schubert, D. Fischer, and J. Heesemann, "Ferric enterochelin transport in Yersinia enterocolitica: molecular and evolutionary aspects," Journal of Bacteriology, vol. 181, no. 20, pp. 6387-6395, 1999.

[41] T. Grant, V. Bennett-Wood, and R. M. Robins-Browne, "Identification of virulence-associated characteristics in clinical isolates of Yersinia enterocolitica lacking classical virulence markers," Infection \& Immunity, vol. 66, no. 3, pp. 1113-1120, 1998.

[42] G. R. Cornelis, A. Boland, A. P. Boyd et al., "The virulence plasmid of Yersinia, an antihost genome," Microbiology and Molecular Biology Reviews, vol. 62, no. 4, pp. 1315-1352, 1998.

[43] J. C. Pepe and V. L. Miller, "Yersinia enterocolitica invasin: a primary role in the initiation of infection," Proceedings of the National Academy of Sciences of the United States of America, vol. 90, no. 14, pp. 6473-6477, 1993.

[44] V. L. Miller, B. B. Finlay, and S. Falkow, "Factors essential for the penetration of mammalian cells by Yersinia," Current Topics in Microbiology and Immunology, vol. 138, pp. 15-39, 1988.

[45] I. Delor and G. R. Cornelis, "Role of Yersinia enterocolitica YST toxin in experimental infection of young rabbits," Infection \& Immunity, vol. 60, no. 10, pp. 4269-4277, 1992.

[46] R. M. Robins-Browne, C. S. Still, M. D. Miliotis, and H. J. Koornhof, "Mechanism of action of Yersinia enterocolitica enterotoxin," Infection \& Immunity, vol. 25, no. 2, pp. 680-684, 1979.

[47] M. Iriarte, J. C. Vanooteghem, I. Delor, R. Diaz, S. Knutton, and G. R. Cornelis, "The Myf fibrillae of Yersinia enterocolitica," Molecular Microbiology, vol. 9, no. 3, pp. 507-520, 1993.

[48] E. Carniel, "The Yersinia high-pathogenicity island," International Microbiology, vol. 2, no. 3, pp. 161-167, 1999.

[49] A. Roggenkamp, T. Bittner, L. Leitritz, A. Sing, and J. Heesemann, "Contribution of the Mn-cofactored superoxide dismutase (SodA) to the virulence of Yersinia enterocolitica serotype O8," Infection \& Immunity, vol. 65, no. 11, pp. 47054710, 1997.

[50] L. Zhang, J. Radziejewska-Lebrecht, D. Krajewska-Pietrasik, P. Toivanen, and M. Skurnik, "Molecular and chemical characterization of the lipopolysaccharide O-antigen and its role in the virulence of Yersinia enterocolitica serotype O:8," Molecular Microbiology, vol. 23, no. 1, pp. 63-76, 1997.

[51] T. F. De Koning-Ward and R. M. Robins-Browne, "Contribution of urease to acid tolerance in Yersinia enterocolitica," Infection \& Immunity, vol. 63, no. 10, pp. 3790-3795, 1995.

[52] R. R. Brubaker, "Factors promoting acute and chronic diseases caused by yersiniae," Clinical Microbiology Reviews, vol. 4, no. 3, pp. 309-324, 1991.

[53] B. Kot, M. Piechota, and A. Jakubczak, "Analysis of occurrence of virulence genes among Yersinia enterocolitica isolates belonging to different biotypes and serotypes," Polish Journal of Veterinary Sciences, vol. 13, no. 1, pp. 13-19, 2010.

[54] L. M. Sihvonen, S. Hallanvuo, K. Haukka, M. Skurnik, and A. Siitonen, "The ail gene is present in some Yersinia enterocolitica biotype 1A strains," Foodborne Pathogens and Disease, vol. 8, no. 3, pp. 455-457, 2011.

[55] M. Shayegani, I. DeForge, D. M. McGlynn, and T. Root, "Characteristics of Yersinia enterocolitica and related species isolated from human, animal, and environmental sources," Journal of Clinical Microbiology, vol. 14, no. 3, pp. 304-312, 1981. 
[56] A. Sulakvelidze, K. Dalakishvili, E. Barry et al., "Analysis of clinical and environmental Yersinia isolates in the Republic of Georgia," Journal of Clinical Microbiology, vol. 34, no. 9, pp. 2325-2327, 1996.

[57] R. Van Noyen, J. Vandepitte, and G. Wauters, "Nonvalue of cold enrichment of stools for isolation of Yersinia enterocolitica serotypes 3 and 9 from patients," Journal of Clinical Microbiology, vol. 11, no. 2, pp. 127-131, 1980.

[58] R. Van Noyen, R. Selderslaghs, G. Wauters, and J. Vandepitte, "Comparative epidemiology of Yersinia enterocolitica and related species in patients and healthy controls," Contributions to Microbiology and Immunology, vol. 9, pp. 61-67, 1987.

[59] C. H. Pai, V. Mors, and T. A. Seemayer, "Experimental Yersinia enterocolitica enteritis in rabbits," Infection \& Immunity, vol. 28, no. 1, pp. 238-244, 1980.

[60] T. Une, "Studies on the pathogenicity of Yersinia enterocolitica. I. Experimental infection in rabbits," Microbiology and Immunology, vol. 21, no. 7, pp. 349-363, 1977.

[61] R. M. Robins-Browne, S. Tzipori, G. Gonis, J. Hayes, M. Withers, and J. K. Prpic, "The pathogenesis of Yersinia enterocolitica infection in gnotobiotic piglets," Journal of Medical Microbiology, vol. 19, no. 3, pp. 297-308, 1985.

[62] I. Singh and J. S. Virdi, "Production of Yersinia stable toxin (YST) and distribution of yst genes in biotype 1A strains of Yersinia enterocolitica," Journal of Medical Microbiology, vol. 53, no. 11, pp. 1065-1068, 2004.

[63] J. G. Morris Jr., V. Prado, C. Ferreccio et al., "Yersinia enterocolitica isolated from two cohorts of young children in Santiago, Chile: incidence of and lack of correlation between illness and proposed virulence factors," Journal of Clinical Microbiology, vol. 29, no. 12, pp. 2784-2788, 1991.

[64] A. P. Burnens, A. Frey, and J. Nicolet, "Association between clinical presentation, biogroups and virulence attributes of Yersinia enterocolitica strains in human diarrhoeal disease," Epidemiology and Infection, vol. 116, no. 1, pp. 27-34, 1996.

[65] M. H. Greenwood and W. L. Hooper, "Excretion of Yersinia spp. associated with consumption of pasteurized milk," Epidemiology and Infection, vol. 104, no. 3, pp. 345-350, 1990.

[66] M. L. Bissett, C. Powers, S. L. Abbott, and J. M. Janda, "Epidemiologic investigations of Yersinia enterocolitica and related species: sources, frequency, and serogroup distribution," Journal of Clinical Microbiology, vol. 28, no. 5, pp. 910 912, 1990.

[67] V. Mors and C. H. Pai, "Pathogenic properties of Yersinia enterocolitica," Infection \& Immunity, vol. 28, no. 1, pp. 292294, 1980.

[68] T. Vesikari, T. Nurmi, and M. Maki, "Plasmids in Yersinia enterocolitica serotypes O:3 and O:9: correlation with epithelial cell adherence in vitro," Infection \& Immunity, vol. 33, no. 3, pp. 870-876, 1981.

[69] D. A. Schiemann and J. A. Devenish, "Relationship of HeLa cell infectivity to biochemical, serological, and virulence characteristics of Yersinia enterocolitica," Infection \& Immunity, vol. 35, no. 2, pp. 497-506, 1982.

[70] I. Bolin, A. Forsberg, L. Norlander, M. Skurnik, and H. Wolf-Watz, "Identification and mapping of the temperatureinducible, plasmid-encoded proteins of Yersinia spp.," Infection \& Immunity, vol. 56, no. 2, pp. 343-348, 1988.

[71] G. Kapperud, E. Namork, M. Skurnik, and T. Nesbakken, "Plasmid-mediated surface fibrillae of Yersinia pseudotuberculosis and Yersinia enterocolitica: relationship to the outer membrane protein YOP1 and possible importance of pathogenesis," Infection \& Immunity, vol. 55, no. 9, pp. 2247-2254, 1987.
[72] D. C. Old and R. A. Adegbola, "Relationships among broadspectrum and narrow-spectrum mannose-resistant fimbrial hemagglutinins in different Yersinia species," Microbiology and Immunology, vol. 28, no. 12, pp. 1303-1311, 1984.

[73] D. C. Old and J. Robertson, "Adherence of fimbriate and nonfimbriate strains of Yersinia enterocolitica to human epithelial cells," Microbiology and Immunology, vol. 25, no. 10, pp. 993998, 1981.

[74] R. R. Isberg, "Discrimination between intracellular uptake and surface adhesion of bacterial pathogens," Science, vol. 252, no. 5008, pp. 934-938, 1991.

[75] R. R. Isberg and P. Barnes, "Subversion of integrins by enteropathogenic Yersinia," Journal of Cell Science, vol. 114, no. 1, pp. 21-28, 2001.

[76] W. H. Lee, P. P. McGrath, P. H. Carter, and E. L. Eide, "The ability of some Yersinia enterocolitica strains to invade HeLa cells," Canadian Journal of Microbiology, vol. 23, no. 12, pp. 1714-1722, 1977.

[77] V. L. Miller, J. B. Bliska, and S. Falkow, "Nucleotide sequence of the Yersinia enterocolitica ail gene and characterization of the ail protein product," Journal of Bacteriology, vol. 172, no. 2, pp. 1062-1069, 1990.

[78] C. Persson, N. Carballeira, H. Wolf-Watz, and M. Fällman, "The PTPase YopH inhibits uptake of Yersinia, tyrosine phosphorylation of $\mathrm{p} 130^{\mathrm{Cas}}$ and FAK, and the associated accumulation of these proteins in peripheral focal adhesions," EMBO Journal, vol. 16, no. 9, pp. 2307-2318, 1997.

[79] R. Zumbihl, M. Aepfelbacher, A. Andor et al., "The cytotoxin YopT of Yersinia enterocolitica induces modification and cellular redistribution of the small GTP-binding protein RhoA," Journal of Biological Chemistry, vol. 274, no. 41, pp. 2928929293, 1999.

[80] D. S. Black and J. B. Bliska, "The RhoGAP activity of the Yersinia pseudotuberculosis cytotoxin YopE is required for antiphagocytic function and virulence," Molecular Microbiology, vol. 37, no. 3, pp. 515-527, 2000.

[81] A. Grutzkau, C. Hanski, H. Hahn, and E. O. Riecken, "Involvement of M cells in the bacterial invasion of Peyer's patches: a common mechanism shared by Yersinia enterocolitica and other enteroinvasive bacteria," Gut, vol. 31, no. 9, pp. 10111015, 1990.

[82] M. A. Clark, B. H. Hirst, and M. A. Jepson, "M-cell surface $\beta 1$ integrin expression and invasin-mediated targeting of Yersinia pseudotuberculosis to mouse Peyer's patch M cells," Infection \& Immunity, vol. 66, no. 3, pp. 1237-1243, 1998.

[83] A. Marra and R. R. Isberg, "Invasin-dependent and invasinindependent pathways for translocation of Yersinia pseudotuberculosis across the Peyer's patch intestinal epithelium," Infection \& Immunity, vol. 65, no. 8, pp. 3412-3421, 1997.

[84] M. Fällman, C. Persson, and H. Wolf-Watz, "Yersinia proteins that target host cell signaling pathways," Journal of Clinical Investigation, vol. 99, no. 6, pp. 1153-1157, 1997.

[85] G. R. Cornelis, “The Yersinia deadly kiss,” Journal of Bacteriology, vol. 180, no. 21, pp. 5495-5504, 1998. 


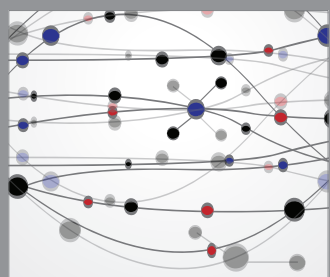

The Scientific World Journal
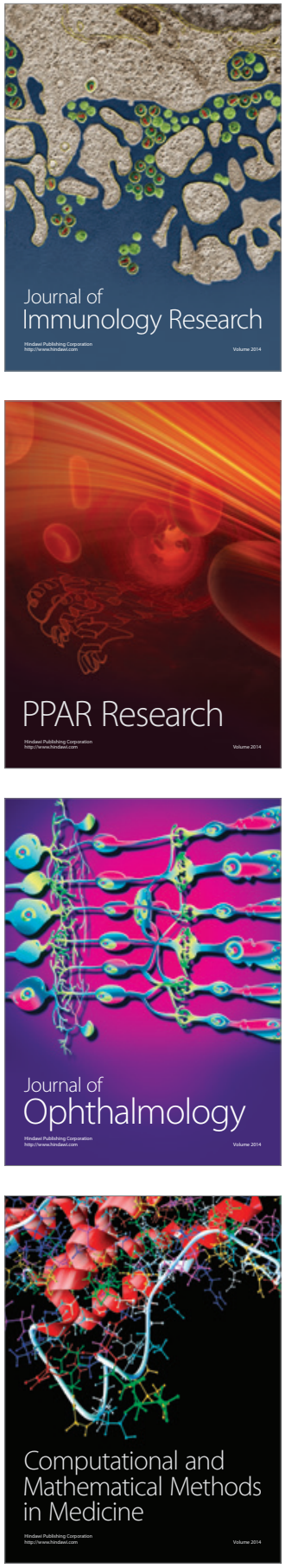

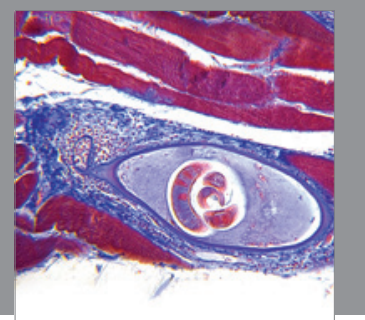

Gastroenterology

Research and Practice
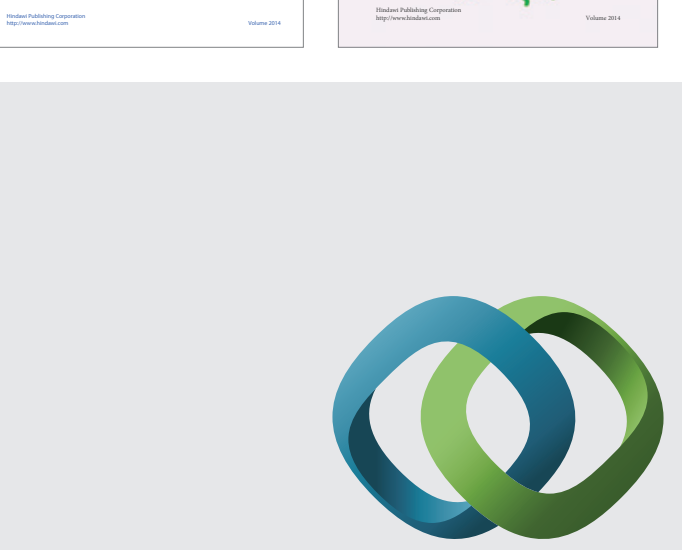

\section{Hindawi}

Submit your manuscripts at

http://www.hindawi.com
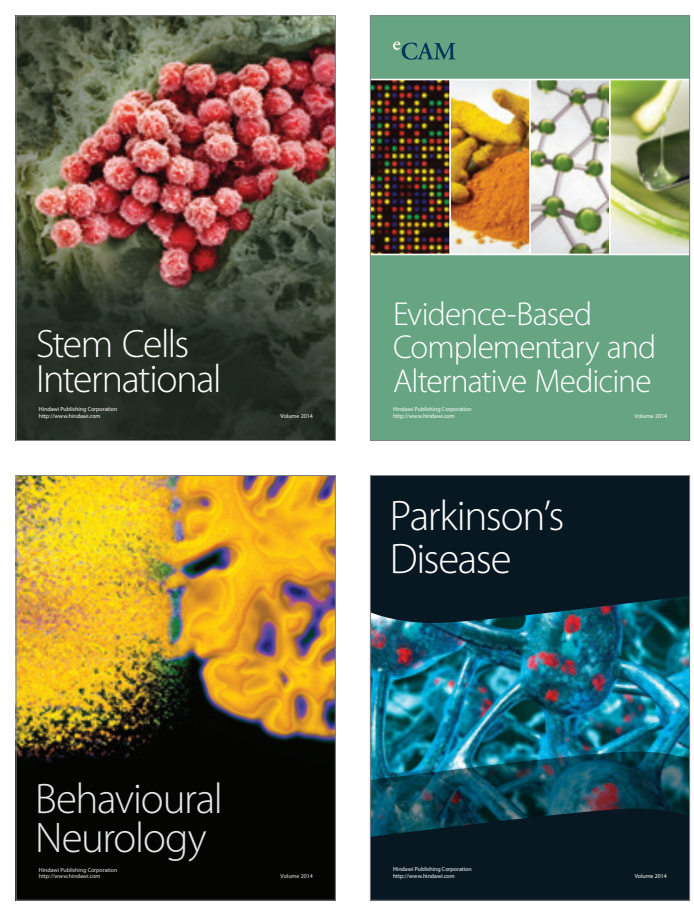

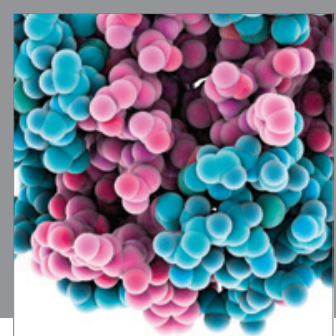

Journal of
Diabetes Research

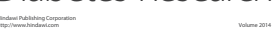

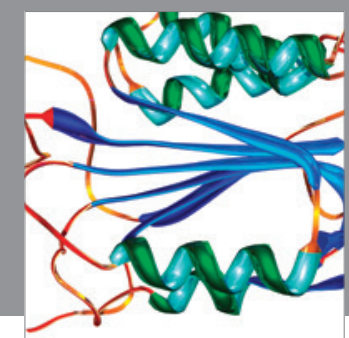

Disease Markers
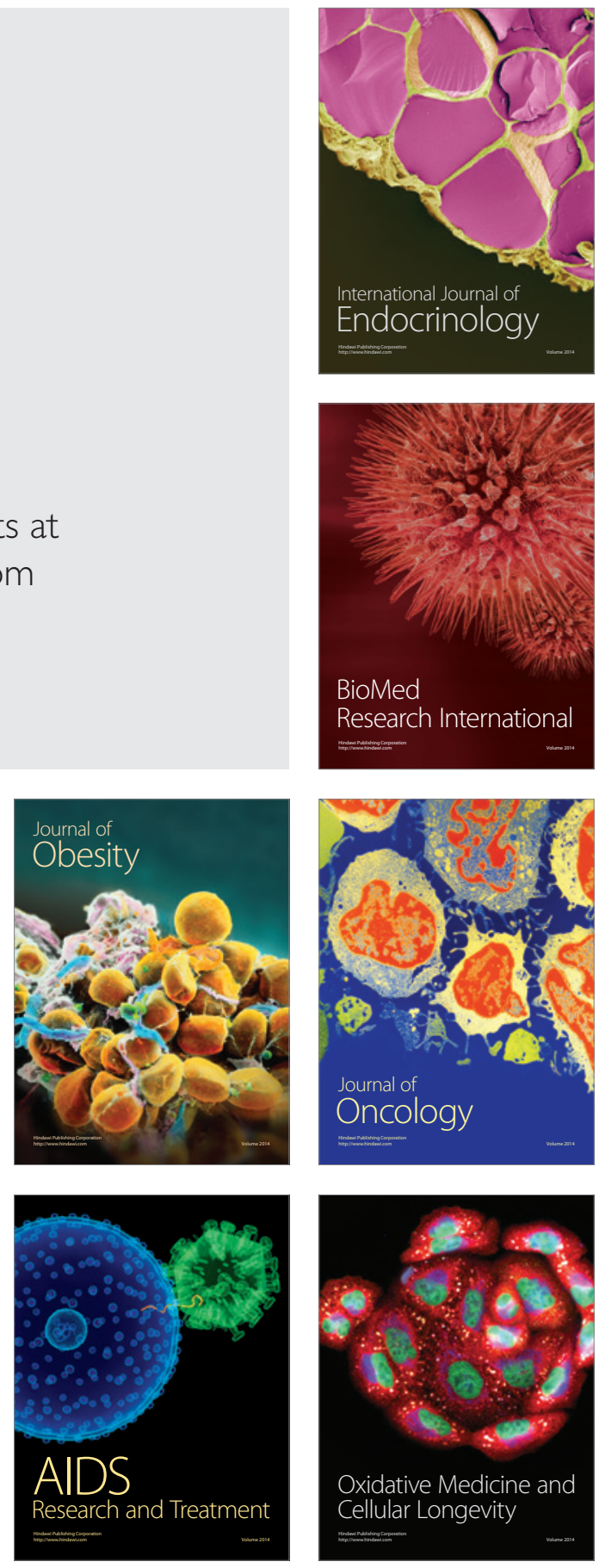